\title{
Reference Value for the Distance Walked in the Six-Minute Walk Test in Obese Brazilian Men in the Preoperative Period of Bariatric Surgery
}

\author{
Cesar Antonio Luchesa $\left(\mathbb{D},{ }^{1,2}\right.$ Thiago Thomaz Mafort $(\mathbb{D}),{ }^{3}$ Rafael Rodrigues da Silva $\left(\mathbb{D},{ }^{2}\right.$

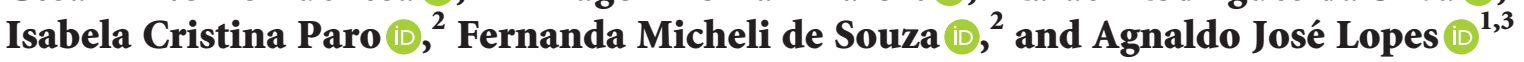 \\ ${ }^{1}$ Rehabilitation Sciences Postgraduation Program, Augusto Motta University Centre (UNISUAM), RJ, Brazil \\ ${ }^{2}$ Rehabilitation Center, University Center Fundação Assis Gurgacz (FAG), Cascavel, PR, Brazil \\ ${ }^{3}$ Medical Sciences Post-Graduation Program, School of Medical Sciences, State University of Rio de Janeiro (UERJ), RJ, Brazil
}

Correspondence should be addressed to Agnaldo José Lopes; agnaldolopes.uerj@gmail.com

Received 27 May 2021; Revised 24 June 2021; Accepted 29 June 2021; Published 8 July 2021

Academic Editor: Nunzio Velotti

Copyright (C) 2021 Cesar Antonio Luchesa et al. This is an open access article distributed under the Creative Commons Attribution License, which permits unrestricted use, distribution, and reproduction in any medium, provided the original work is properly cited.

\begin{abstract}
Background. Obesity has several effects on the mechanics of the rib cage that may impair the exercise performance of obese individuals and therefore impact the assessment of surgical risk. This study aimed to establish a reference value for the 6-minute walk distance (6 MWD) in obese Brazilian men in the preoperative period of bariatric surgery that considers the effect of lung function. Methods. This was a cross-sectional study in which 104 obese men underwent the six-minute walk test (6 MWT) before bariatric surgery. They also underwent the spirometry test and respiratory muscle strength measurement before the $6 \mathrm{MWT}$. Results. The 6MWD was correlated with age $(r=-0.388, p=0.0005)$, weight $(r=-0.365, p=0.0007)$, height $(r=0.285$, $p=0.022)$, body mass index (BMI) $(r=-0.543, p<0.0001)$, forced vital capacity (FVC) $(r=0.472, p<0.0001)$, peak expiratory flow $(r=0.253, p=0.031)$, and maximal inspiratory pressure $(r=0.313, p=0.017)$. In the stepwise forward regression analysis, $\mathrm{BMI}, \mathrm{FVC}$, and age were the only variables that independently predicted the $6 \mathrm{MWD}$ and explained $40 \%$ of its variability. The reference equation proposed for obese Brazilian men is $6 \mathrm{MWD}(m)=570.5-\left(3.984 \times \mathrm{BMI}_{\mathrm{kg} / \mathrm{m} 2}\right)+(1.093 \times \mathrm{FVC} \%$ predicted $)-\left(0.836 \times\right.$ age $\left._{\mathrm{yrs}}\right)$. Conclusion. In this sample of obese Brazilian men, lung function contributed to poor performance in the $6 \mathrm{MWT}$. In these individuals, BMI, FVC, and age were the variables that composed the reference equation for the $6 \mathrm{MWD}$. Thus, in several clinical settings, such as in the evaluation before bariatric surgery, pulmonary function data are important to determine the reference value for the $6 \mathrm{MWD}$.
\end{abstract}

\section{Introduction}

Obesity hinders walking and is therefore an important component of functional limitation, which can be caused by a sedentary lifestyle and the numerous adverse effects of excess weight $[1,2]$. Obese individuals have a lower exercise capacity not only because walking is a weightbearing activity but also because these individuals have significant comorbidities [3]. The six-minute walk test (6 MWT) is a measure of functional capacity and is a lowcost and easy-to-administer tool to measure submaximal loads during exercise [4]. To better understand the $6 \mathrm{MWT}$, values that predict the six-minute walk distance (6 MWD) should be carefully selected [5]. However, 6 MWT reference values for healthy, normal-weight individuals are of limited value for obese subjects because physiological factors, including a lower tolerance to effort, together with a higher prevalence of comorbid conditions, are responsible for the consistently lower $6 \mathrm{MWD}$ in obese individuals [6].

The performance of an obese individual in the $6 \mathrm{MWT}$ should be evaluated considering the various repercussions 
that obesity causes in the body [6]. In addition to causing mechanical compression of the lungs and thoracic cavity, obesity increases both the neural respiratory drive and the thoracic blood volume [7], resulting in a reduction in thoracic compliance, impairment of diaphragmatic function, and an increase in respiratory work, which negatively impact lung function [8].

Although spirometry test results have been used in preoperative assessments of obese people, their relationship with the functional capacity of obese individuals is uncertain $[9,10]$. Considering the need to estimate cardiopulmonary function in the preoperative evaluation for bariatric surgery and to establish the surgical risk, knowing the influence of lung function measurements on the $6 \mathrm{MWD}$ is important $[1,9-12]$. Thus, we aimed to establish a reference value for the $6 \mathrm{MWD}$ in obese Brazilian men in the preoperative period of bariatric surgery that considers the effect of lung function.

\section{Materials and Methods}

2.1. Study Design and Participants. A cross-sectional study was conducted between March 2020 and February 2021 with 104 obese men (of 123 eligible) in the preoperative period before bariatric surgery at the University Center Fundação Assis Gurgacz, Cascavel, PR, Brazil. All individuals older than 18 years with a body mass index $(B M I) \geq 30 \mathrm{~kg} / \mathrm{m}^{2}[13]$ who attended the centre throughout the study course were invited to join. These volunteers were recruited by an advertisement in the centre. Individuals who reported smoking (smoking load $\geq 10$ pack-years), subjects with a previous report of cardiopulmonary or neuromuscular disorders or lower limb fractures, and those with difficulties completing the protocol tests (spirometry test and the $6 \mathrm{MWT}$ ) were excluded.

The study protocol was approved by the research ethics committee of our institution under CAAE no. 11613219.0.0000.5219, and all participants read and signed the informed consent form.

2.2. Lung Function. The spirometry test was performed using a MicroLoop device (ML3535, Micro Medical, Kent, UK) according to the recommendations of the American Thoracic Society/European Respiratory Society [14]. Respiratory muscle strength was measured using a GlobalMed digital manometer (MVD 300, Porto Alegre, Brazil). We used Brazilian reference values to express the variables of pulmonary function tests as percentages of predicted values $[15,16]$.

2.3. Six-Minute Walk Test. The $6 \mathrm{MWT}$ was performed according to previously described recommendations using a $30 \mathrm{~m}$ runway demarcated with cones at both ends [17]. Blood pressure, heart rate, respiratory rate, peripheral oxygen saturation $\left(\mathrm{SpO}_{2}\right)$, and Borg's perceived exertion scale were measured before and after the $6 \mathrm{MWT}$. The examiner also used words of encouragement every minute. At the end of the sixth minute, the stop point and the $6 \mathrm{MWD}$ were recorded. Thirty minutes after the first $6 \mathrm{MWT}$, the participants performed a second $6 \mathrm{MWT}$ to avoid possible learning and adaptation effects, as observed in conditions affecting the respiratory system [18]. Only the test with the highest 6 MWD was considered for analysis.

2.4. Data Analysis. Parametric methods were applied because the variables showed a Gaussian distribution according to the Shapiro-Wilk test, and a graphical analysis of histograms was performed. For the test-retest reliability analysis, a two-way random-effects intraclass correlation coefficient (ICC) was calculated using a confidence interval of $95 \%$ (95\% CI). The correlations of the $6 \mathrm{MWD}$ with anthropometric, demographic, and pulmonary function data were analysed by Pearson's coefficient. Stepwise forward linear regression analysis was applied to identify independent variables that explained the 6MWD and generate the reference equation for $6 \mathrm{MWD}$. The results are expressed as the mean \pm standard deviation (SD) or frequency (percentage), and statistical significance was accepted at $p<0.05$.

Calibration was verified using a limits of agreement (LoA) plot with the Bland-Altman method and a calibration plot (the observed vs. predicted $6 \mathrm{MWD}$ along with regression lines showing the slope and intercept). Data analysis was performed using SAS 6.11 software (SAS Institute, Inc., Cary, NC, USA).

Post hoc power analysis using GPower 3.1.1 software based on an a priori type I error $\alpha=0.05$ (two-tailed) and a complete-case analysis showed that the observed significant effects were detected with a power in the range of $73 \%$ to $99 \%$.

\section{Results}

Among the 123 obese subjects who were eligible for the study, 19 were excluded for the following reasons: individuals with a smoking load $\geq 10$ pack-years $(n=10)$; reporting prior cardiopulmonary disease $(n=5)$; history of lower limb surgery $(n=2)$; and difficulties in performing acceptable manoeuvres in the spirometry test $(n=2)$. No patients refused to perform the $6 \mathrm{MWT}$.

The mean age was $41.4 \pm 12.2$ years, and $21(20.2 \%)$ had a history of smoking (smoking load $<10$ pack-years). The mean BMI was $48.1 \pm 8.4 \mathrm{~kg} / \mathrm{m}^{2}$, while the mean $6 \mathrm{MWD}$ was $439.1 \pm 82.3 \mathrm{~m}$. No participant showed a decrease $\geq 4 \%$ in $\mathrm{SpO}_{2}$ at the end of the $6 \mathrm{MWT}$.

According to the spirometry test, 38 (36.5\%) and 30 (28.8\%) participants had a forced vital capacity (FVC) and peak expiratory flow (PEF) $<80 \%$ of the predicted values, respectively, and no patient showed a forced expiratory volume in one second $\left(\mathrm{FEV}_{1}\right) / \mathrm{FVC}<70 \%$. According to measurements of respiratory muscle strength, the maximal inspiratory pressure (MIP) and maximal expiratory pressure were $<80 \%$ of the predicted values in $23(22.1 \%)$ and 16 (15.4\%) participants, respectively. Anthropometric, demographic, pulmonary function, and $6 \mathrm{MWT}$ data are shown in Table 1. 
TABle 1: Anthropometric and demographic data, lung function, and six-minute walk test results of the evaluated sample.

\begin{tabular}{lc}
\hline Variables & Values $(n=104)$ \\
\hline Anthropometric and demographic variables & \\
Age (years) & $41.4 \pm 12.2$ \\
Weight (kg) & $146.5 \pm 27.5$ \\
Height (m) & $1.74 \pm 0.1$ \\
BMI (kg/m ${ }^{2}$ ) & $48.1 \pm 8.4$ \\
\hline Lung function & \\
FVC (\% predicted) & $83.5 \pm 16.1$ \\
PEF (\% predicted) & $90.1 \pm 21.1$ \\
FEV $/$ FVC (\%) & $85.4 \pm 6.5$ \\
MIP (\% predicted) & $95.3 \pm 12.8$ \\
MEP (\% predicted) & $85.4 \pm 13.3$ \\
\hline Six-minute walk test & \\
6 MWD (m) & $439.2 \pm 82.7$ \\
\hline
\end{tabular}

The results are expressed as the means \pm SD; BMI: body mass index; FVC: forced vital capacity; PEF: peak expiratory flow; $\mathrm{FEV}_{1}$ : forced expiratory volume in one second; MIP: maximal inspiratory pressure; MEP: maximal expiratory pressure; $6 \mathrm{MWD}$ : six-minute walk distance.

When comparing the means of the two $6 \mathrm{MWT}$ trials performed by the participants, no significant difference was noted, although the distance covered in the second $6 \mathrm{MWT}$ was longer $(451.4 \pm 87.5 \mathrm{~m}$ vs. $430.6 \pm 79.3 \mathrm{~m}$, $p=0.79$ ]; $81 \%$ of the participants performed better on the second test. Highly significant intraobserver agreement was observed between the measurements of the two $6 \mathrm{MWT}$ trials $\quad(\mathrm{ICC}=0.92, \quad 95 \% \quad \mathrm{CI}=0.85-0.97$; $p<0.0001)$.

We evaluated the correlations between the $6 \mathrm{MWD}$ and the anthropometric, demographic, and pulmonary function data. In this analysis, significant positive correlations were observed between the $6 \mathrm{MWD}$ and the following variables: height $(r=0.285, p=0.022)$, FVC $(r=0.472, p<0.0001)$, PEF $(r=0.253, p=0.031)$, and MIP $(r=0.313, p=0.017)$. Significant negative correlations were observed between the $6 \mathrm{MWD}$ and the following variables: age $(r=-0.388$, $p=0.0005)$, weight $(r=-0.365, p=0.0007)$, and BMI $(r=-0.543, p<0.0001)$ (Figure 1).

Finally, we evaluated whether the anthropometric, demographic, and pulmonary function variables could predict performance during the $6 \mathrm{MWT}$ using nine predictor variables. In the stepwise forward regression analysis, BMI, FVC, and age were the only variables that independently predicted $6 \mathrm{MWD}$, and these variables explained $40 \%$ of its variability (Table 2). The reference equation proposed was as follows: $6 \mathrm{MWD} \quad(m)=570.5-\left(3.984 \times \mathrm{BMI}_{\mathrm{kg} / \mathrm{m} 2}\right)+\left(1.093 \times \mathrm{FVC}_{\%}\right.$ predicted $)-\left(0.836 \times\right.$ age $\left._{\mathrm{yrs}}\right) ; R^{2}=0.40$ (standard error of the regression coefficient $=47.3 \mathrm{~m}$ ).

Regarding the calibration of the regression model, most differences were within the LoA, with a random distribution over the mean values in the range of the highest concentration (350-500 m). However, a slight bias was observed for high and low values of the distance covered (Figure 2). Additionally, no clear relationship was detected between the differences (bias) and the mean (given by the straight line), and the fitted line had a slight slope in relation to the main diagonal (Figure 3).

\section{Discussion}

The main finding of the present study was that, in a population of obese men with a high BMI in the preoperative period before surgery, obesity, BMI, FVC, and age were independent factors predicting the $6 \mathrm{MWD}$. In addition, the 6 MWT was highly reproducible in these individuals, although a second test showed greater distance walked, possibly due to a learning effect. In this study, the reference equation for the $6 \mathrm{MWD}$ in obese Brazilian men obtained shortly before bariatric surgery was reported for the first time. These results are important in risk assessment and fitness assessment before bariatric operations.

$6 \mathrm{MWT}$ outcomes are associated with daily physical activity and can also be considered a direct measure of impaired quality of life [19]. The $6 \mathrm{MWD}$ is highly correlated with exercise measurements on a stationary bicycle or treadmill and has the advantage of reflecting a subject's usual activities [20]. Despite the importance of the $6 \mathrm{MWT}$, research on its value for the obese population is limited. In addition, almost all previous studies involving the $6 \mathrm{MWT}$ have been performed in samples predominantly composed of obese women, who have very different performance from that observed in obese men during submaximal exercise $[3,6,11,19,21]$. Similar to Wooldridge et al. [4], Vanhelst et al. [22], and Hulens et al. [23], we observed that BMI was one of the most important variables in the reference equation for the $6 \mathrm{MWD}$ of obese subjects, which is not surprising because excess weight increases the workload and affects walking due to trunk oscillation and the increased distance between the feet [2]. Age was also a variable that was included in the reference equation for the $6 \mathrm{MWD}$ in this population. In addition to being overweight, obese individuals are thought to suffer many of the effects of age on functional capacity, including changes in the osteoarticular and neuromuscular systems related to ageing [24].

The $6 \mathrm{MWT}$ evaluates the global and integrated responses of all systems involved in exercise, including the respiratory system. Obesity causes numerous repercussions for the respiratory system, including reduced lung compliance and increased surface tension of the alveoli due to a lower functional residual capacity and airway closure, with the formation of atelectatic areas $[25,26]$. Excess fat in the thorax may also increase pulmonary resistance and even promote changes in the ventilation/perfusion ratio due to hypoxemia and possibly to the closure of small airways $[7,27]$. Since obesity can compress the lungs and the rib cage, we thought that subjects in the preoperative period of bariatric surgery might have worse performance during the $6 \mathrm{MWT}$ due to the decrease in lung function. In fact, pulmonary function-more precisely, the FVC that reduces restrictive ventilatory impairment in the spirometry test-negatively impacted 6 MWD in our explanatory model for obese Brazilian men. The deposition of fat in the thoracoabdominal region is one of the main mechanisms responsible for the reduction in lung volume, promotes changes in the compliance of the respiratory system, and worsens the performance of the muscles responsible for breathing [28]. 


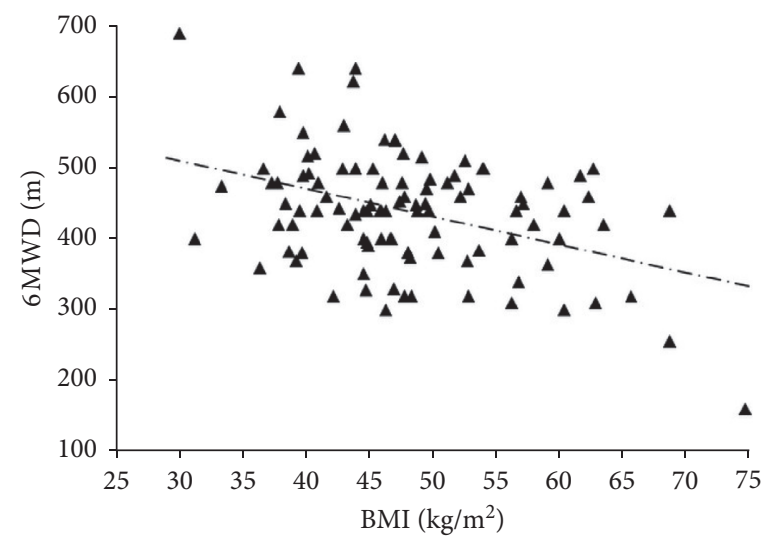

(a)

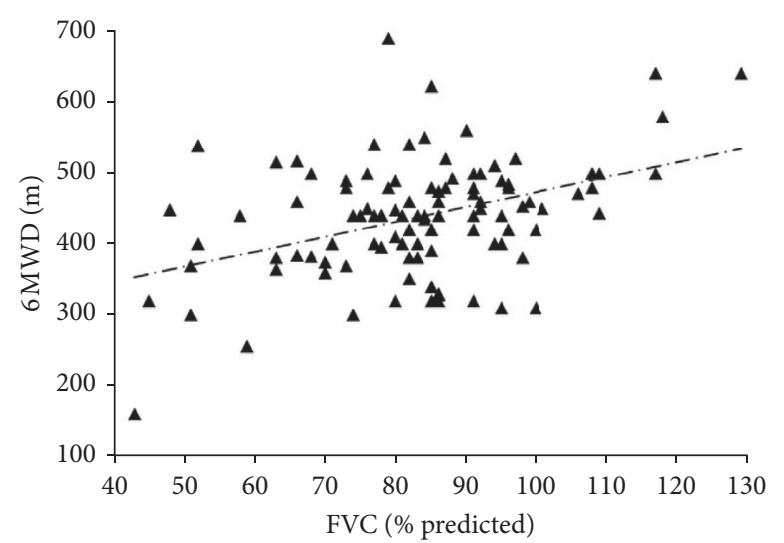

(b)

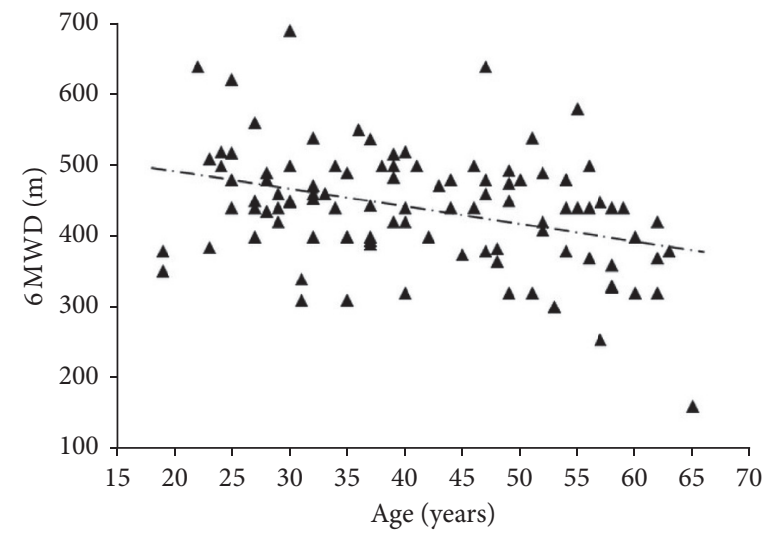

(c)

FIGURE 1: Relationships of the six-minute walk distance (6 MWD) with (a) body mass index (BMI, r) $=-0.543, p<0.0001$ ), (b) forced vital capacity (FVC, $\mathrm{r})=0.472, p<0.0001)$, and (c) age $(r=-0.388, p=0.0005)$.

TABLE 2: Multiple regression model for the six-minute walk distance of obese men using demographic and anthropometric data and lung function variables.

\begin{tabular}{lcccc}
\hline Independent variables & $\mathrm{B}$ & $\mathrm{SEB}$ & $p$ value & Cumulative $R^{2 *}$ \\
\hline Constant & 560.5 & 47.3 & $<0.0001$ & \\
BMI & -3.984 & 0.481 & $<0.0001$ & 0.30 \\
FVC & 1.093 & 0.222 & 0.0007 & 0.36 \\
Age & -0.836 & 0.290 & 0.008 & 0.40 \\
\hline
\end{tabular}

B: regression coefficient; SEB: standard error of the regression coefficient: $R^{2}$, adjusted determination coefficient: BMI: body mass index; FVC: forced

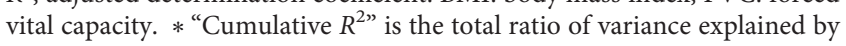
the model.

Interestingly, the pattern of body fat distribution as determined by anthropometric measurements or complementary tests such as dual-energy X-ray absorptiometry seems to be relevant to the changes in lung function observed in obese people. The android pattern with fat accumulation in the abdominal region seems to have a more negative impact on lung function, as it causes greater impairment of ventilatory mechanics and increases resistance to diaphragmatic contraction. This phenomenon explains the greater FVC impairment in obese men than in women of

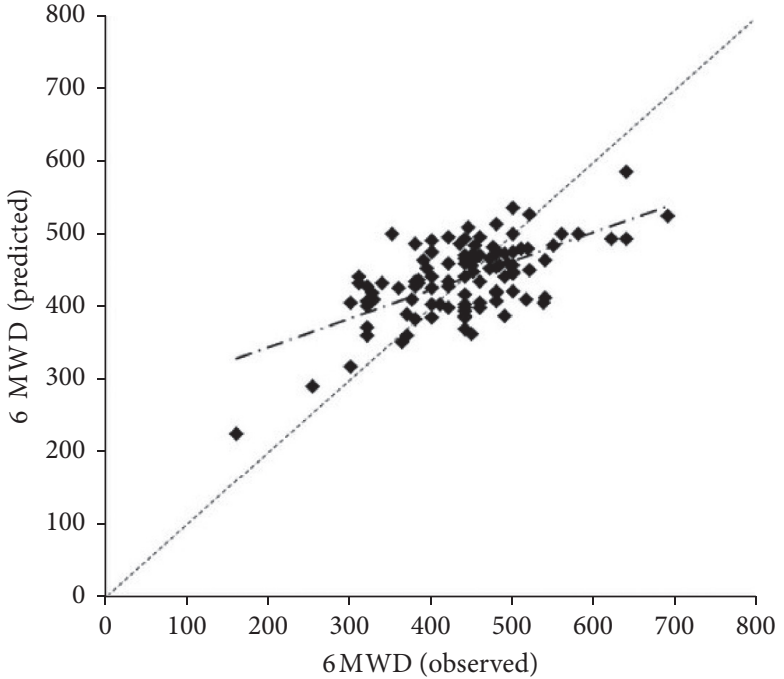

FIGURE 2: Limits of agreement plot of the averaged values and differences (observed-predicted values) for the $6 \mathrm{MWD}$; the mean difference was zero with a standard deviation of $64 \mathrm{~m}$ and the corresponding $95 \%$ limits of agreement were $-126 \mathrm{~m}$ (lower) and $+126 \mathrm{~m}$ (upper). 


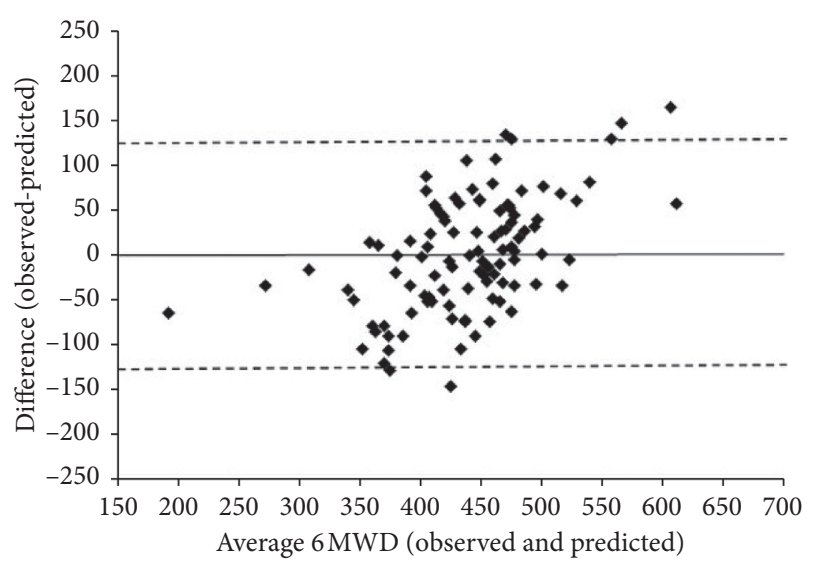

FIGURE 3: Calibration plot of the observed vs. predicted values for the 6 MWD; Pearson's correlation coefficient between the observed and predicted 6 MWD was $r=0.65(p<0.0001)$.

the same BMI since in women, the predominant pattern of fat accumulation is gynoid, where fat accumulation occurs in the gluteofemoral region [29, 30].

Reliability, repeatability, and reproducibility are three of the fundamental properties of a test and are influenced by many factors [31]. The reproducibility of the $6 \mathrm{MWT}$ has been evaluated in different studies (including in patients with and without respiratory diseases) and with various testretest intervals [32-35]. Despite its excellent reproducibility, there is strong evidence of a learning effect for the $6 \mathrm{MWD}$ when two or more tests are conducted [18]. The present results showed that the $6 \mathrm{MWT}$ is reproducible in obese individuals; however, $81 \%$ of the subjects showed greater distance walked in the second test. Although the $6 \mathrm{MWT}$ is reliable, patients improve their performance when performing the second test, probably because they underestimate their functional capacity $[18,35]$. Other proposed mechanisms for increasing performance with test repetition include familiarity with the walking course, improved pacing, and increased motivation [32]. These results should encourage professionals to assess the $6 \mathrm{MWT}$ twice, especially when using this test as an outcome measure (e.g., assessing the impact of bariatric surgery on functional capacity).

In our reference equation, BMI, FVC, and age explained $40 \%$ of the 6 MWD variability. Few studies have evaluated the impact of lung function on the $6 \mathrm{MWD}$ in obese and nonobese individuals. Camarri et al. [36] evaluated 70 Caucasian subjects and showed that height and $\mathrm{FEV}_{1}$ were the only significant independent predictors of $6 \mathrm{MWD}$, which explained $33.9 \%$ of the variance in their model. In their study, most individuals $(63 \%)$ were overweight or obese, although the entire group had median $\mathrm{FEV}_{1}$ and FVC values within the normal ranges. Unlike our model, their 6 MWD explanatory model did not include BMI, possibly because few subjects had a BMI $>30 \mathrm{~kg} / \mathrm{m}^{2}$. In obese Brazilian women, it was recently shown that BMI, FVC, age, and maximal inspiratory pressure explained $41 \%$ of the variability in $6 \mathrm{MWD}$ [7]. Since we evaluated a population in the preoperative period before bariatric surgery, our results may better reflect the physical fitness of individuals with a high $\mathrm{BMI}$ and their need for surgical intervention.

The reference equations for the $6 \mathrm{MWD}$ in healthy adults (men and women) by Enright and Sherrill [37] are among the oldest and most used, and therefore, it is worth highlighting them. In men, these authors found that age, body weight, and height were independently associated with the distance covered in the $6 \mathrm{MWT}$. Similar to our findings, approximately $60 \%$ of the variance in $6 \mathrm{MWD}$ remained unexplained in their gender-specific models. Although Enright and Sherrill's equations have been used in clinical practice in subjects with different BMIs, the conversion factors in the formula are unreliable because these equations were originally validated for BMI $<35 \mathrm{~kg} / \mathrm{m}^{2}$ [6]. Furthermore, their study excluded subjects with $\mathrm{FEV}_{1}<70 \%$ of the predicted value, although lung function is a major contributor to performance during the $6 \mathrm{MWT}$ in obese people $[12,36]$.

Our study has limitations. First, the present study evaluated only obese men, precluding extrapolation of our results to obese men of other age groups, such as adolescents and elderly men. Second, we used only spirometry tests and measurements of respiratory muscle strength. More complex pulmonary function analysis tools, such as whole-body plethysmography, the forced oscillation technique, and carbon monoxide diffusion capacity, may better predict the impact of lung function on the $6 \mathrm{MWD}$. Our reference value of the $6 \mathrm{MWD}$ in obese men may serve as a useful reference for future clinical and research studies. Future studies should also evaluate the impact of other organ systems that are known to be compromised in obesity, such as the cardiovascular and musculoskeletal systems.

\section{Conclusions}

In this sample of obese Brazilian men, lung function contributed to poor performance in the $6 \mathrm{MWT}$. In these individuals, BMI, FVC, and age were the variables that composed the reference equation for the $6 \mathrm{MWD}$. Thus, in the preoperative evaluation before weight loss surgery, pulmonary function data are important to determine the reference value for the $6 \mathrm{MWD}$ in obese Brazilian men.

\section{Data Availability}

The data used to support the findings of this study are available from the corresponding author upon reasonable request.

\section{Conflicts of Interest}

The authors declare that they have no conflicts of interest.

\section{Acknowledgments}

This study was supported by the Conselho Nacional de Desenvolvimento Científico e Tecnológico (CNPq) (Grant nos. 407138/2018-8 and 302215/2019-0), the Fundação Carlos Chagas Filho de Amparo à Pesquisa do Estado do Rio de Janeiro (FAPERJ) (Grant nos. \#E-26/202.679/2018 and 
\#E-26/010.002124/2019), and the Coordenação de Aperfeiçoamento de Pessoal de Nível Superior (CAPES) (Finance Code 001).

\section{References}

[1] S. A. F. De Souza, J. Faintuch, S. M. Fabris et al., "Six-minute walk test: functional capacity of severely obese before and after bariatric surgery," Surgery for Obesity and Related Diseases, vol. 5, no. 5, pp. 540-543, 2019.

[2] G. Correia de Faria Santarém, R. De Cleva, M. A. Santo et al., "Correlation between body composition and walking capacity in severe obesity," PLoS One, vol. 10, no. 6, Article ID e0130268, 2015.

[3] L. M. Donini, E. Poggiogalle, V. Mosca, A. Pinto, A. Brunani, and P. Capodaglio, "Disability affects the 6-minute walking distance in obese subjects (BMI $>40 \mathrm{~kg} / \mathrm{m}^{2}$ ), PLoS One, vol. 8 , no. 10, Article ID e75491, 2013.

[4] J. S. Wooldridge, M. S. Herbert, J. Hernandez et al., "Improvement in 6-min walk test distance following treatment for behavioral weight loss and disinhibited eating: an exploratory secondary analysis," International Journal of Behavioral Medicine, vol. 26, no. 4, pp. 443-448, 2019.

[5] C. Casanova, B. R. Celli, P. Barria et al., "The 6-min walk distance in healthy subjects: reference standards from seven countries," European Respiratory Journal, vol. 37, no. 1, pp. 150-156, 2011.

[6] P. Capodaglio, S. A. De Souza, C. Parisio et al., "Reference values for the 6-min walking test in obese subjects," Disability and Rehabilitation, vol. 35, no. 14, pp. 1199-1203, 2013.

[7] T. T. Mafort, R. Rufino, C. H. Costa, and A. J. Lopes, "Obesity: systemic and pulmonary complications, biochemical abnormalities, and impairment of lung function," Multidisciplinary Respiratory Medicine, vol. 11, no. 1, p. 28, 2016.

[8] T. M. D. C. S. Carvalho, A. F. Soares, D. C. S. Climaco, I. V. Secundo, and A. M. J. d. Lima, "Correlation of lung function and respiratory muscle strength with functional exercise capacity in obese individuals with obstructive sleep apnea syndrome," Jornal Brasileiro de Pneumologia, vol. 44, no. 4, pp. 279-284, 2018.

[9] A. Van Huisstede, L. U. Biter, R. Luitwieler et al., "Pulmonary function testing and complications of laparoscopic bariatric surgery," Obesity Surgery, vol. 23, no. 10, pp. 1596-1603, 2013.

[10] D. Clavellina-Gaytán, D. Velázquez-Fernández, E. Del-Villar et al., "Evaluation of spirometric testing as a routine preoperative assessment in patients undergoing bariatric surgery," Obesity Surgery, vol. 25, no. 3, pp. 530-536, 2015.

[11] C. B. Vargas, F. Picolli, C. Dani, A. V. Padoin, and C. C. Mottin, "Functioning of obese individuals in pre- and postoperative periods of bariatric surgery," Obesity Surgery, vol. 23, no. 10, pp. 1590-1595, 2013.

[12] C. A. Luchesa, T. T. Mafort, R. R. Silva, I. C. Paro, F. M. Souza, and A. J. Lopes, "Contribution of lung function in predicting distance covered in the 6-min walk test in obese Brazilian women," Brazilian Journal of Medical and Biological Research, vol. 53, no. 12, Article ID e10279, 2020.

[13] World Health Organization, Obesity and Overweight-Fact Sheet $N^{\circ} 311$, World Health Organization, Geneva, Switzerland, 2020, http://www.who.int/mediacentre/factsheets/fs311/ en/.

[14] M. R. Miller, J. Hankinson, V. Brusasco et al., "Standardisation of spirometry," European Respiratory Journal, vol. 26, no. 2, pp. 319-338, 2005.
[15] J. A. Neder, S. Andreoni, M. C. Lerario, and L. E. Nery, "Reference values for lung function tests: II. Maximal respiratory pressures and voluntary ventilation," Brazilian Journal of Medical and Biological Research, vol. 32, no. 6, pp. 719-727, 1999.

[16] C. A. D. C. Pereira, T. Sato, and S. C. Rodrigues, "Novos valores de referência para espirometria forçada em brasileiros adultos de raça branca," Jornal Brasileiro de Pneumologia, vol. 33, no. 4, pp. 397-406, 2007.

[17] ATS Committee on Proficiency Standards for Clinical Pulmonary Function Laboratories, "ATS statement," American Journal of Respiratory and Critical Care Medicine, vol. 166, no. 1, pp. 111-117, 2002.

[18] A. E. Holland, M. A. Spruit, T. Troosters et al., "An official European Respiratory Society/American Thoracic Society technical standard: field walking tests in chronic respiratory disease," European Respiratory Journal, vol. 44, no. 6, pp. 1428-1446, 2014.

[19] M. J. Ekman, M. Klintenberg, U. Björck, F. Norström, and M. Ridderstråle, "Six-minute walk test before and after a weight reduction program in obese subjects," Obesity, vol. 21, no. 3, pp. E236-E243, 2013.

[20] K. Beriault, A. C. Carpentier, C. Gagnon et al., "Reproducibility of the 6-minute walk test in obese adults," International Journal of Sports Medicine, vol. 30, no. 10, pp. 725-727, 2009.

[21] N. N. Crispim Carvalho, V. J. Baccin Martins, J. ModestoFilho, F. Bandeira, F. C. Fernandes Pimenta, and J. L. De Brito Alves, "Relationship between skeletal muscle mass indexes and muscular function, metabolic profile and bone mineral density in women with recommendation for bariatric surgery," Diabetes, Metabolic Syndrome and Obesity: Targets and Therapy, vol. 12, pp. 2645-2654, 2019.

[22] J. Vanhelst, P. S. Fardy, J. Salleron, and L. Béghin, "The sixminute walk test in obese youth: reproducibility, validity, and prediction equation to assess aerobic power," Disability and Rehabilitation, vol. 35, no. 6, pp. 479-482, 2013.

[23] M. Hulens, G. Vansant, A. L. Claessens, R. Lysens, and E. Muls, "Predictors of 6-minute walk test results in lean, obese and morbidly obese women," Scandinavian Journal of Medicine \& Science in Sports, vol. 13, no. 2, pp. 98-105, 2003.

[24] V. P. Almeida, A. S. Ferreira, F. S. Guimarães, J. Papathanasiou, and A. J. Lopes, "Predictive models for the six-minute walk test considering the walking course and physical activity level," European Journal of Physical and Rehabilitation Medicine, vol. 55, no. 6, pp. 824-833, 2019.

[25] C. M. Salome, G. G. King, and N. Berend, "Physiology of obesity and effects on lung function," Journal of Applied Physiology, vol. 108, no. 1, pp. 206-211, 2010.

[26] D. J. Brazzale, J. J. Pretto, and L. M. Schachter, "Optimizing respiratory function assessments to elucidate the impact of obesity on respiratory health," Respirology, vol. 20, no. 5, pp. 715-721, 2015.

[27] P. L. Gontijo, T. P. Lima, T. R. Costa, E. P. Dos Reis, F. P. De Faria Cardoso, and F. F. Cavalcanti Neto, "Correlation of spirometry with the six-minute walk test in eutrophic and obese individuals," Revista da Associação Médica Brasileira (English Edition), vol. 57, no. 4, pp. 380-386, 2011.

[28] R. L. Jones and M.-M. U. Nzekwu, "The effects of body mass index on lung volumes," Chest, vol. 130, no. 3, pp. 827-833, 2006.

[29] G. Enzi, M. Gasparo, P. R. Biondetti, D. Fiore, M. Semisa, and F. Zurlo, "Subcutaneous and visceral fat distribution according to sex, age, and overweight, evaluated by computed 
tomography," The American Journal of Clinical Nutrition, vol. 44, no. 6, pp. 739-746, 1986.

[30] R. M. Steele, F. M. Finucane, S. Griffin, N. J. Wareham, U. Ekelund, and U. Ekelund, "Obesity is associated with altered lung function independently of physical activity and fitness," Obesity, vol. 17, no. 3, pp. 578-584, 2009.

[31] J. W. Bartlett and C. Frost, "Reliability, repeatability and reproducibility: analysis of measurement errors in continuous variables," Ultrasound in Obstetrics and Gynecology, vol. 31, no. 4, pp. 466-475, 2008.

[32] S. Jenkins and N. M. Cecins, "Six-minute walk test in pulmonary rehabilitation: do all patients need a practice test?" Respirology, vol. 15, no. 8, pp. 1192-1196, 2010.

[33] J. Adsett, R. Mullins, R. Hwang et al., "Repeat six-minute walk tests in patients with chronic heart failure: are they clinically necessary?" European Journal of Cardiovascular Prevention \& Rehabilitation, vol. 18, no. 4, pp. 601-606, 2011.

[34] B. A. Pankoff, T. J. Overend, S. D. Lucy, and K. P. White, "Reliability of the six-minute walk test in people with fibromyalgia," Arthritis \& Rheumatism, vol. 13, no. 5, pp. 291-295, 2000.

[35] E. E. Kakitsuka, A. A. Morita, E. Y. Itakussu et al., "Six-minute walk test in burned subjects: applicability, reproducibility and performance at hospital discharge," Burns, vol. 46, no. 7, pp. 1540-1547, 2020.

[36] B. Camarri, P. R. Eastwood, N. M. Cecins, P. J. Thompson, and S. Jenkins, "Six minute walk distance in healthy subjects aged 55-75 years," Respiratory Medicine, vol. 100, no. 4, pp. 658-665, 2006.

[37] P. L. Enright and D. L. Sherrill, "Reference equations for the six-minute walk in healthy adults," American Journal of Respiratory and Critical Care Medicine, vol. 158, no. 5 Pt 1, pp. 1384-1387, 1998. 